Article

\title{
Modelling Market Volatility with Univariate GARCH Models: Evidence from Nasdaq-100
}

\author{
Fuzuli Aliyev ${ }^{1,}$, Richard Ajayi $^{2}$ and Nijat Gasim ${ }^{3}$ \\ 1 Finance Department, Baku Engineering University, Baku AZ0101, Azerbaijan; faliyev@beu.edu.az \\ 2 Finance Department, University of central Florida, Orlando 32816, United States of America; \\ rajayi@bus.ucf.edu \\ 3 Econometrics Department, Dokuz Eylul University, Izmir 35220, Turkey; nicatgasim@gmail.com \\ * Correspondence: e- faliyev@beu.edu.az; Tel.: +994504651228
}

\begin{abstract}
This paper models and estimates the volatility of nonfinancial, innovative and hi-tech focused stock index, the Nasdaq-100, using univariate symmetric and asymmetric GARCH models. We employ GARCH, EGARCH and GJR-GARCH using daily data over the period January 4, 2000 through March 19, 2019. We find that the volatility shocks on the index returns are quite persistent. Furthermore, our findings show that the index has leverage effect, and the impact of shocks is asymmetric, whereby the impacts of negative shocks on volatility are higher than those of positive shocks of the same magnitude.
\end{abstract}

Keywords: Volatility, Risk, Nasdaq-100, GARCH models, Leverage Effect

\section{Introduction}

All stakeholders in financial markets, especially investors are concerned with risks of the assets they invest in. Modelling and predicting financial assets' volatility is an important signal for investors to balance their portfolios. Thus, academicians as well as practitioners have developed many models to analyze asset volatility. In general, volatility is a measure of the variance of returns on a time series of asset prices over a given period (Cizeau et al (1997)) and it quantifies the risk related to that asset. Financial asset returns are commonly characterized by volatility clustering, that is, extended periods of "violent" or high market volatility followed by a period of high volatility, and "calm" or low market volatility followed by period of low volatility (Tsay (2010)). Additionally, financial time series tend to exhibit negative skewness, excess kurtosis, and temporal persistence in conditional variance (Andersen eta al (2001)). Besides these, financial assets returns are observed to often have thicker tails than expected under normality. Some studies propose that these tails might be so thick as to have come from a Cauchy distribution, or other distributions with infinite moments (Mandelbrot (1963)).

Under linear assumptions, these stylized facts of financial time series may introduce errors into the analysis of financial asset prices. Nevertheless, recent studies in the literature show that financial time series, most of the time, exhibit nonlinear dynamics (Franses and van Dijk (2000); Kumar Narayan (2005)). Time series nonlinearities may manifest from either conditional variance or conditional mean, or both. Nonlinear time series of conditional mean are modeled through threshold autoregressive models (TAR) or Markov switching models. However, if the nonlinearity is a result of conditional variance, such series are modeled with autoregressive conditional heteroscedasticity (ARCH) models developed by Engle (1982). Engel's model describes the variance of the current error 
term as a function of the previous periods' error terms. Bollerslev (1986) advanced Engle's model to Generalized Autoregressive Conditional Heteroskedasticity model (GARCH) to allow for changes in the time dependent volatility, such as decreasing or increasing volatility in the same series. Since then, there have been several derivations of the GARCH model, with letters from alphabet coming before the root name. The volatility clustering implied by $\mathrm{ARCH}$ and $\mathrm{GARCH}$ models also implies thicker tails than normal (Levendis, (2018)).

This paper models the volatility of Nasdaq-100, a nonfinancial, innovative and hi-tech stock, index's returns by employing various univariate conditional heteroscedasticity models. To this end, we examine the volatility of Nasdaq-100 index using symmetric and asymmetric models, namely GARCH, EGARCH and GJR-GARCH models with daily closing prices of the index over the sample space of January 4, 2000 to March 19, 2019. By so doing, we are addressing the gap in the literature on volatility analysis of the Nasdaq-100 index with symmetric and asymmetric models through extended time span covering the 2008 financial crisis and its aftermath.

Nasdaq-100 (NDX) is a young high-tech-focused index covering companies from telecom to biotechnology and it is the world's preeminent large-cap growth index. With technology influencing the world more and more each day and making companies more efficient and interdependent, paying attention to the technology sector is very appropriate. Nasdaq-100, with its large exposure towards technology, also closely tracks the volatility of S\&P 500, the main peer equity index (Nasdaq web page (2019)). To the best of our knowledge, there are no studies in the literature that comprehensively investigate the dynamics of Nasdaq-100 daily index return volatility with symmetric and asymmetric GARCH models over a very long period of time, in this case $2000-2019$. The remaining part of the paper is organized as follows: Section two presents the Literature Review while section three describes the Methodology used. Data and Empirical Results are set forth in section four and section five presents the Summary and Conclusion.

\section{Literature Review}

There are many studies in the literature using GARCH type and other approaches to model financial assets volatility. Our objective in this paper is to investigate the volatility of Nasdaq-100 index and to that end, we focus on reviewing previous studies done on this index. At the same time, we start first by briefly examining studies that investigate the volatility of stock indexes at emerging and developing economies.

Abdalla and Winker (2012) estimate the volatility of Egyptian and Sudanese markets for the period of January 2006 to November 2010 by employing symmetric and asymmetric GARCH models. They report conditional volatility of returns of explosive and quite persistent nature for both countries. Ugurlu et al (2014) uses GARCH, GJR-GARCH and EGARCH models to examine the volatility of stock indexes from five European emerging markets, namely Turkey, Bulgaria, Czech Republic, Poland and Hungary. They find volatility shocks that are persistent at those markets and conclude that the impact of old news is significant on volatility. Koy and Ekim (2016) apply GARCH, EGARCH and TGARCH models to illustrate volatility of four Borsa Istanbul sub-indexes for the period of 2011-2014. They find no significant asymmetric impact of shocks on the volatility of banking shares, while all other sub-indices exhibit asymmetry.

Lu and Perron (2010) use random level shift model (incorporated into GARCH) to simulate and forecast volatility of four US stock market indices including Nasdaq. Their findings show that level shift model successfully captures long-memory and conditional heteroscedasticity, and it 
outperforms GARCH $(1,1)$ model in forecasting. On their part, Chu and Lam (2011) address limitations of Andersen and Bollerslev's (1997) sequential estimation method for modeling an intraday volatility process. With 10-min returns of the Nasdaq composite stock index from15 August 2005 to 12 September 2008, they search for better ARCH parameters, and propose an approach that considers the interaction effect between the periodicity and the heteroscedasticity. Chen et al (2012) study volatility of thirty most actively traded Nasdaq stocks with after-hours information added to GARCH model. They find pre-open coefficients in the model to be positive and significant for 23 of the 30 stocks, however the post-close variance to have less power in predicting the future conditional volatility. Caporale and Gil-Alana (2011) examine volatility persistence and long-memory property of Nasdaq-100 index with daily data from January2, 2001 to February 20, 2004. Utilizing Gaussian semiparametric method, they find that the Nasdaq-100 volatility has long memory with the effect of the shocks fading out in the long run, and the mean reversion process holds. Molnár (2016) employs Range-GARCH $(1,1)$ model to investigate volatility at six stock indices including Nasdaq-100 with daily data. He finds Nasdaq volatility to be explosive (1.028 value of $\alpha+\beta)$ with R-GARCH model, which outperforms standard GARCH $(1,1)$ model in forecasting. However, his R-GARCH model does not capture leverage effect in the Nasdaq-100 series. In their recent study Augustyniak et al (2018) propose Factorial Hidden Markov Volatility model, a new approach, to simulate volatility of the Nasdaq-100 index among other series. Their new approach outperforms other peer methods at modelling and forecasting Nasdaq-100 return series volatility at short and long-run horizons. Altun (2018) applies two-sided Lomax distribution to GJR-GARCH models to forecast value-at-risk. He uses daily Nasdaq-100 index data for the period of 14 March 2014 - 13 April 2018 and finds that GJRGARCH model produce more accurate forecasts under two-sided Lomax distribution, and successfully models skewness and excess kurtosis of the index. Moreover, very recently, Chang et al (2019) propose modified Grey-GARCH model to investigate the volatility of the daily dynamics of Nasdaq closing prices. Comparing their suggested model with ordinary Grey-GARCH and standard GARCH model, they find that Nasdaq-100 index prices' volatility can be modelled and forecasted better with their model.

This paper contributes to the literature with its focus on modeling Nasdaq-100 index volatility with symmetric and asymmetric univariate GARCH models through extended period covering the 2008 financial crisis and its aftermath.

\section{Methodology}

\subsection{The GARCH model}

Since financial markets data often exhibit varying volatility, autoregressive (AR) and moving average (MA) models, that assume the conditional variances are constant, cannot capture the nonlinear dynamics. Linear models are unable to explain characteristics like volatility clustering, leverage effects, leptokurtosis and long memory in financial series (Zivot (2009). Thus, we employ an econometric method that allows modeling nonlinear patterns as non-constant volatility. Autoregressive conditional heteroscedasticity $(\mathrm{ARCH})$ and its derivative models are popularly utilized in modelling and forecasting asset dynamics. Bollerslev (1986) extended Engle's work (1982) and developed the technique that allows for both autoregressive (AR) and moving average (MA) components in the heteroskedastic variance. This is the generalized Autoregressive Conditional Heteroscedasticity, GARCH $(p, q)$, model. The goal of this type of model is to develop a volatility 
measure that can be used in financial decision-making process. General GARCH model expresses the variance as:

$\sigma_{t}^{2}=\alpha_{0}+\sum_{i=1}^{q} \alpha_{i} \varepsilon_{t-i}^{2}+\sum_{j=1}^{p} \beta_{j} \sigma_{t-j}^{2}$

where, $\sigma_{t}^{2}$ is conditional variance, $\varepsilon t$ is return residual and $\alpha_{0}, \alpha_{i}, \beta_{j}$ are parameters to be estimated. The necessary condition for the positive variance is nonnegative value of $\alpha_{0}, \alpha_{i}, \beta_{j}$ parameters, and $\alpha_{i}+\beta_{j}$ is expected to be less than 1 for the model to be valid. In financial data series analysis, higher values of $\alpha_{i}$ coefficient imply higher reaction of volatility to market shocks, while higher values of $\beta_{j}$ coefficient shows persistence of market shocks.

Brooks and Burke (2010) suggest that GARCH $(1,1)$ model is sufficient to capture the volatility clustering in financial data. In this paper we follow Brooks and Burke's suggestion and use GARCH $(1,1)$ with the following equations:

Mean equation $\quad r_{t}=\mu+\varepsilon_{t}$

Variance equation $\sigma_{t}^{2}=\alpha_{0}+\alpha_{1} \varepsilon_{t-1}^{2}+\beta_{1} \sigma_{t-1}^{2}$

with $\alpha_{0}>0$ and $\alpha_{1} \geq 0$ and $\beta_{1} \geq 0$ conditions.

where $r_{t}$ is the return of the asset at time $t, \mu$ is average return and $\varepsilon_{t}$ is residual return. Since $\sigma_{t}^{2}$ is the variance at time $t$ based on the past information at time $t-1$, it is called conditional variance. The conditional variance equation (3) above is a function of three variables: a constant term $\left(\alpha_{0}\right)$, volatility news at the previous period $\left(\varepsilon_{t-1}^{2}\right.$ or $\mathrm{ARCH}$ term), calculated as the lag of the squared residuals from the mean equation (3.2.2) and the variance at previous period ( $\sigma_{t-1}^{2}$ or GARCH term). That means conditional variance of $\varepsilon$ at time $t$ depends not only on the news about volatility from the previous period, but also on the last period conditional variance.

To estimate the model, the mean return equation (2) is first estimated to get the residuals from the regression, which in turn will be utilized to test for ARCH and GARCH effects. Then, squared residuals series and conditional variance are regressed on their lags. The null hypothesis of no GARCH effects (that is there are no volatility clustering in the Nasdaq-100 returns) suggests that $\alpha_{0}$, $\alpha_{1}$ and $\beta_{1}$ parameters be nonnegative to make conditional variance $\sigma_{t}^{2}$ nonnegative. The sum of $\alpha_{1}$ and $\beta_{1}$ coefficients is a measure of persistence of volatility shocks and is expected to be less than 1 . The sum of coefficients higher than 1 means the shock has explosive effect.

\subsection{The Exponential GARCH model}

Standard GARCH models assume that positive and negative error terms have a symmetric effect on the volatility. However, financial time series in practice exhibit asymmetrical nonlinear patterns because of various reasons such as transaction costs, market frictions, arbitrage limits and others (Aliyev (2019)). This means that the impact of "bad news" or negative shocks on conditional volatility may persist longer than impact of "good news" or positive shocks. GARCH model is unable to capture this leverage effect. The model that allows for the asymmetric effect of news is the Exponential GARCH (EGARCH) model proposed by Nelson (1991). This model allows for asymmetric reaction of conditional variance to shocks, and the EGARCH $(1,1)$ is written as:

Mean equation $\quad r_{t}=\mu+\varepsilon_{t}$

Variance equation $\ln \left(\sigma_{t}^{2}\right)=\alpha_{0}+\beta_{1} \ln \left(\sigma_{t-1}^{2}\right)+\alpha_{1}\left[\left|\frac{\varepsilon_{t-1}}{\sigma_{t-1}}\right|-\sqrt{\frac{2}{\pi}}\right]-\gamma \frac{\varepsilon_{t-1}}{\sigma_{t-1}}$ 
where $\gamma$ denotes leverage effects which accounts for the asymmetry of the model. If $\gamma<0$ it means negative shocks (bad news) generate more volatility than positive shocks (good news), however $\gamma>0$ means positive news are more destabilizing than negative ones. $\gamma=0$ shows the model to be symmetric. Since $\ln \left(\sigma_{t}^{2}\right)$ may be negative, there are no sign restrictions for the parameters.

\subsection{The GJR-GARCH model}

Another model that accounts for asymmetry is GJR-GARCH model proposed by Glosten, Jagananthan and Runkle (1993). The model is a simple extension of standard GARCH, which allows the conditional variance to have a different response to past positive and negative shocks. The model's conditional variance can be written as:

$u_{t}^{2}=\alpha_{0}+\alpha_{1} u_{t-1}^{2}+\beta \sigma_{t-1}^{2}+\gamma u_{t-1}^{2} I_{t-1}$

where $I_{t-1}$ is a dummy variable and:

$I_{t-1}=\left\{\begin{array}{c}1 \text { if } u_{t-1}<0, \quad \text { positive shock } \\ 0 \text { if } u_{t-1} \geq 0, \text { negative shock }\end{array}\right\}$

The coeffieincts at the equation (5) $\gamma>0$ and $\gamma \neq 0$ show leverage effect and asymmetric shocks respectively. The condition for non-negativity is $\alpha_{0}>0, \alpha_{1}>0, \beta \geq 0$ and $\alpha_{1}+\gamma \geq 0$ (Brooks, 2008:405).

\section{Data and Empirical Findings}

\subsection{Data}

We use daily Nasdaq-100 closing price data over the period January 4, 2000 through March 19, 2019 to model the volatility of the index's returns. This index includes 100 of the largest domestic and international non-financial companies across major industry groups including IT, retail/wholesale trade and biotechnology listed on the Nasdaq Stock Market. The data is obtained from Bloomberg terminal. To reduce change range and heteroscedasticity we use return $\left(r_{t}\right)$ data, and generate this by dividing the price at time $t\left(p_{t}\right)$ by the preceding price $\left(p_{t-1}\right)$ and taking the natural logarithm, and that is the logarithmic first difference:

$$
r_{t}=\ln \left(\frac{p_{t}}{p_{t-1}}\right)
$$

where $r_{t}$ is the daily return, $p_{t}$ and $p_{t-1}$ denote the index price for the day $t$ and $t$ - 1 respectively. Figure 1 plots the pattern of price and return graphs of the index under review.

Figure 1: Nasdaq-100 index price (left) and return (right) series graph
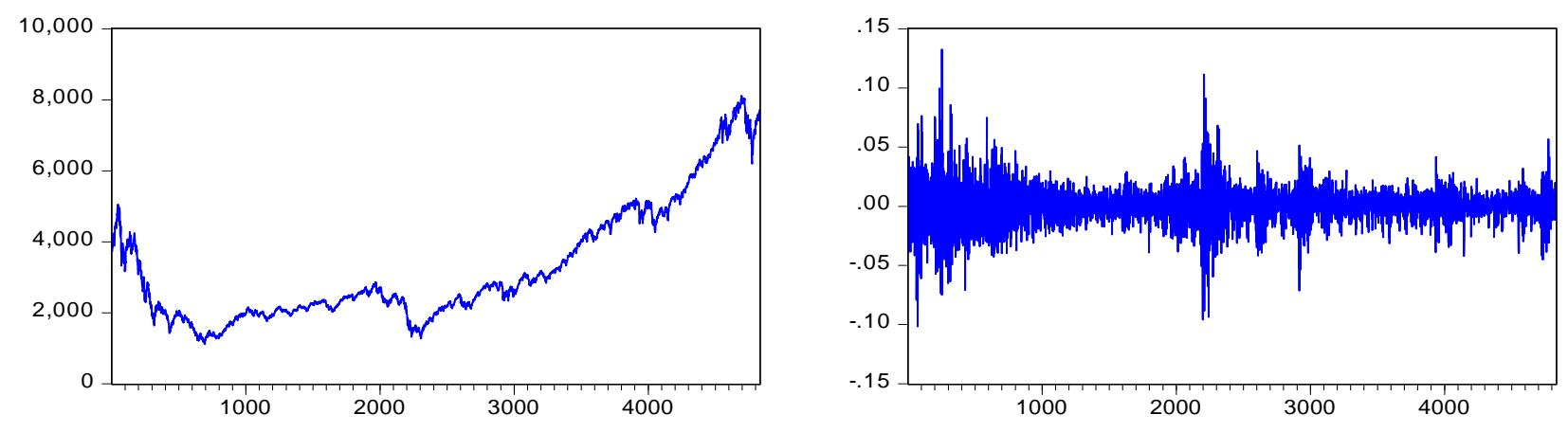
The 4830 observations in the $r_{t}$ series have a mean value of 0.0000141 and a sample standard deviation of 0.015791 . Table 1 reports descriptive statistics of the data. The distribution of returns remarkably differs from normality given the excess kurtosis and light right skewness implying some asymmetry. Heavy tailed leptokurtic distribution implies the index has low risk and return in the sample space. Consequently, based on the Jarque-Bera statistic, the null hypothesis of normality for the daily Nasdaq-100 is rejected at the 1\% significance level.

Table 1: Descriptive statistics of the Nasdaq-100 return series

\begin{tabular}{|c|c|c|}
\hline Statistics & Value & Histogram \\
\hline Mean & 0.000141 & 36 \\
\hline Median & 0.000837 & $32-$ \\
\hline Maximum & 0.132546 & $28-$ \\
\hline Minimum & -0.101684 & $24-$ \\
\hline Standard deviation & .0015791 & 16 \\
\hline Skewness & 0.006345 & $12-$ \\
\hline Kurtosis & 8.861645 & \\
\hline Jarque-Bera & 6914.757 & 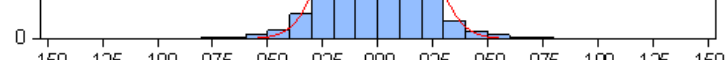 \\
\hline Prob. of Jarque-Bera & 0.000000 & \begin{tabular}{|l}
$\square$ Histogram — Normal \\
\end{tabular} \\
\hline
\end{tabular}

Stationarity of the series is tested with Augmented Dickey-Fuller (Dickey and Fuller, 1981) and Phillips-Perron (Phillips and Perron, 1988) unit root tests and reported on Table 2. Both test results reject null hypothesis that the return series has a unit root and that means the Nasdaq-100 return series is stationary in the period under study.

Table 2: Unit root test results

\begin{tabular}{|l|c|c|c|}
\hline & $\boldsymbol{t}$-Statistic & Critical values at 5\% level & Prob. \\
\hline ADF test statistic & -52.96390 & -2.861943 & 0.0001 \\
\hline PP test statistic & -72.02785 & -2.861943 & 0.0001 \\
\hline Ho: Nasdaq-100 return series has a unit root & & \\
\hline
\end{tabular}

\section{2 Empirical Results}

To model volatility and persistence at the Nasdaq-100 index we use GARCH $(1,1)$ model that is a simplification of equation (3). After trying several ARMA $(p, q)$ models we reached best fitting model. Then as a first step to test for conditional heteroscedasticity, we apply the Lagrange Multiplier (LM) test proposed by Engle (1982). To this end, et is estimated from the ordinary least squares regression, then squared residuals are regressed on a constant and $q$ own lags to test ARCH order, as in the following equation:

$e_{t}^{2}=\alpha_{0}+\alpha_{1} e_{t-1}^{2}+\alpha_{2} e_{t-2}^{2}+\cdots+\alpha_{q} e_{t-q}^{2}+v_{t}$ 
where $v_{t}$ is an error term. The test statistic is calculated as number of observations $(N)$ times the $R^{2}$ obtained from the regression 4.1. The value of the test statistic $\left(N R^{2}\right)$ is evaluated against $\chi^{2}(q)$ distribution. Following this procedure, we first regress return series $\left(y_{t}\right)$ on its mean and obtain residuals. We then test the null hypothesis that there are no ARCH effects in the residuals. The results of this ARCH-LM test are reported in Table 3. These results reject $H_{0}$ and show that the series has ARCH effect on the residuals, implying that variance of returns of Nasdaq-100 series are nonconstant. Additionally, the volatility clustering pattern observed on return series graph depicted on Figure 1 above suggests ARCH type model, as well.

Table 3: ARCH-LM test results

\begin{tabular}{|c|c|}
\hline ARCH-LM statistic & Prob. Chi-square (1) \\
\hline 4811.700 & 0.0000 \\
\hline$H_{0}:$ There are no ARCH effect on residuals \\
\hline
\end{tabular}

Since the residuals have ARCH effects we employ GARCH process to model this conditional heteroscedasticity. Considering that the data is not normally distributed we estimate the model with Student's $t$ distribution. Iterating Marquardt steps to maximize log likelihood function we estimate GARCH parameters and obtain $\operatorname{ARMA}(1,1)$ mean equation. Estimation results are reported on Table 4. Results show that constant term $\left(\alpha_{0}\right)$, ARCH term $\left(\alpha_{1}\right)$ and GARCH term $\left(\beta_{1}\right)$ are statistically significant. This means that conditional variance has correlation with lagged conditional variance and lagged squared disturbance, or financial news about volatility today has explanatory power on the next period's volatility. The model output is shown on Appendix 1.

The reported $\alpha_{1}$ measures the extent to which a volatility shock today feeds through into next period's volatility (Campbell et al. 1997). For our series, Nasdaq-100, this coefficient is 0.090591 and this shows the presence of volatility clustering in the series over the period. The estimate of $\beta_{1}$ coefficient 0.906023 indicates a long memory in the variance. This indicates that changes in the current volatility will affect future volatilities for a long period or the impact of old news on volatility is long lasting. The sum of ARCH and GARCH terms $\alpha_{1}+\beta_{1}$ is 0.996614 indicating volatility shocks are quite persistent. The financial implication of these coefficients for investors is that Nasdaq-100 index returns' volatility exhibits clustering, and this permits investors to establish future positions in expectation of this characteristic.

Table 4: Estimation results of GARCH models

\begin{tabular}{|c|c|c|c|c|c|c|}
\hline \multirow{2}{*}{ Parameter } & \multicolumn{2}{c|}{ GARCH (1, 1) } & \multicolumn{2}{c|}{ EGARCH } & \multicolumn{2}{c|}{ GJR-GARCH } \\
\cline { 2 - 7 } & Coef. & Prob. & Coef. & Prob. & Coef. & Prob. \\
\hline \multicolumn{7}{|c|}{ Mean equation } \\
\hline$C$ & 0.000915 & 0.0001 & - & 0.000575 & 0.001 \\
\hline$A R(1)$ & 0.812776 & 0.0001 & - & \multicolumn{2}{c|}{-} \\
\hline$M A(1)$ & -0.842160 & 0.0001 & - & 0.0000174 & 0.0000 \\
\hline \multicolumn{7}{|c|}{ Variance equation } \\
\hline$\alpha_{0}$ & 0.0000013 & 0.0001 & -0.20935 & 0.0000 & 0.0000 & 0.9483 \\
\hline$\alpha_{1}$ & 0.090591 & 0.0000 & -0.119352 & 0.0000 & -0.000546 & 0.0000 \\
\hline$\beta_{1}$ & 0.906023 & 0.0000 & 0.987505 & 0.0000 & 0.911589 & 0 \\
\hline
\end{tabular}




\begin{tabular}{|c|c|c|c|c|c|c|}
\hline$\gamma$ & \multicolumn{2}{|c|}{-} & 0.122569 & 0.0000 & 0.153715 & 0.0000 \\
\hline$\alpha_{1}+\beta_{1}$ & \multicolumn{2}{|c|}{0.996614} & \multicolumn{2}{|c|}{0.868153} & \multicolumn{2}{|c|}{0.912135} \\
\hline Log likelihood & \multicolumn{2}{|c|}{14476.43} & \multicolumn{2}{|c|}{14543.63} & \multicolumn{2}{|c|}{14532.17} \\
\hline ARCH-LM test & 1.413528 & 0.2345 & 2.259458 & 0.1328 & 8.142256 & 0.1486 \\
\hline
\end{tabular}

We apply Engle- $\mathrm{Ng}$ (1993) test to determine if the series require asymmetric model. The test is applied to residuals of $\operatorname{GARCH}(1,1)$ model. Firstly, to find out if the volatility is sign biased, we test significance of $\varphi_{1}$ in the equation (8).

$u_{t}^{2}=\varphi_{0}+\varphi_{1} S_{t-1}^{-}+v_{t}$

From the test results (see Appendix 2) the coefficient of dummy of negative shock $\left(\varphi_{1}\right)$ is statistically significant, and this means positive and negative shocks impact asymmetrically on conditional variance. Then, negative shock bias test results (see Appendix 3) show that the asymmetry comes from negative shocks. Finally, joint test for sign and size bias based on equation (9) finds $\varphi_{2}$ and $\varphi_{3}$ significant.

$u_{t}^{2}=\phi_{0}+\varphi_{1} S_{t-1}^{-}+\varphi_{2} S_{t-1}^{-} u_{t-1}+\varphi_{3} S_{t-1}^{+} u_{t-1}+v_{t}$

Results (see Appendix 4) show that negative shock decreases conditional variance by 0.019 times whereas positive shock only increases by 0.009 times. To test the null hypothesis of no asymmetric effects we calculate $N R^{2}$ from the equation (9), that asymptotically follows $\chi^{2}$ distribution, and find $365.16>7.81$. We reject null hypothesisand this means that magnitude of negative shocks is not the same as that of postivie shocks.

To capture the asymmetric impact of different type of news (or leverage effect), we employ EGARCH and GJR-GARCH models. An advantage of the EGARCH model in comparison with basic GARCH model is that the conditional variance, $\sigma_{t}^{2}$, is guaranteed to be positive regardless of the values of the coefficients in equation 6 , even if the parameters are negative, the log of conditional variance will be positive (Zivot (2008)). As shown at the EGARCH $(1,1)$ column of the Table 4 (see Appendix 5 for model output), all estimates are statistically significant. $\gamma$ the leverage coefficient, is negative (-0.119352) and significant, indicating the presence of an asymmetric behavior. This means that, within the period under study, negative shocks (bad news) have higher impact on next period's volatility than positive shocks (good news) of the same magnitude. In the real world, investors are more responsive to the negative news in comparison to positive news and implies that the volatility spillover mechanism is asymmetric. Since asymmetry coefficient, 0.122569 is positive, it is expected that the relationship between the past variance and the current variance is positive in absolute value. Furthermore, at the bottom of the QQ-plot in Figure 2 we see EGARCH model residuals deviate from normality and this once again shows higher impact of negative shocks (bottom of graph) on volatility. 
Figure 2: Normal Quantile-Quantile Plots of the EGARCH residuals

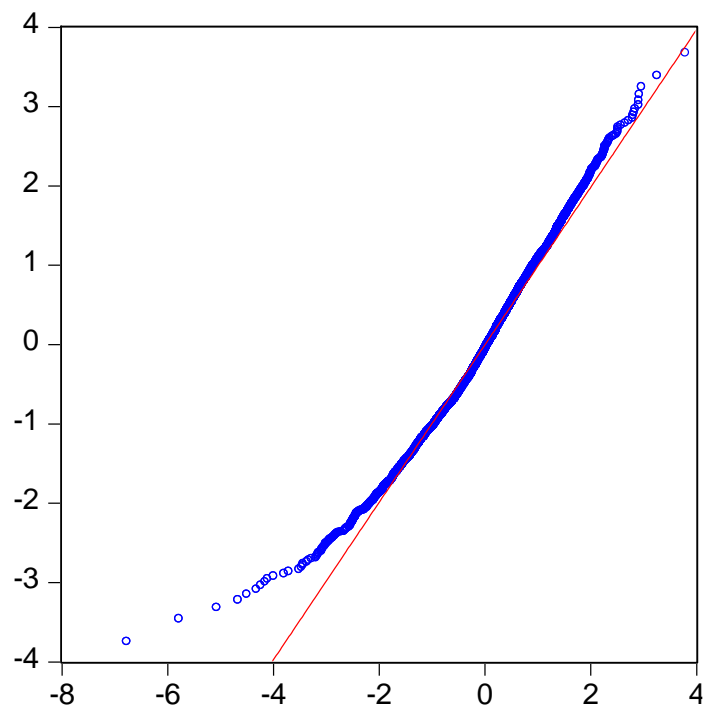

GJR-GARCH model results are reported in the fourth column of Table 4 (see Appendix 6 for model output). The asymmetry term $\gamma$ is positive and statistically significant, that means the impact of shocks is asymmetric and negative shocks increase volatility.

The lower rows of the Table 4 report the results of diagnostic tests for remaining ARCH effects. The ARCH-LM test statistics for both models indicate no ARCH effect remaining in the residuals of the models.

\section{Conclusion}

Most financial time series exhibit autocorrelation and volatility clustering which are inconsistent, with the assumptions in traditional econometric models. This paper uses standard GARCH, asymmetric EGARCH and GJR-GARCH models to analyze volatility in Nasdaq-100 index returns for the period of January 4, 2000 to March 19, 2019. These models are capable of capturing symmetric and asymmetric dynamics such as leptokurtosis, volatility clustering, and leverage effects of the return series. To the best of our knowledge, there are no studies in the literature that comprehensively investigate the dynamics of Nasdaq-100 daily index return volatility especially covering the period of 2008 financial crisis and its aftermath.

The results show that Nasdaq-100 index returns deviate from normality and exhibit volatility clustering with varying variance in the residuals. These findings show nonlinear structure in the conditional variance of the returns and this dynamic may be simulated with the GARCH $(1,1)$ model. Estimates of the model $\left(\alpha_{1}+\beta_{1}\right)$ show the variance of the series has long memory and shocks on volatility are quite persistent, but non-unity, and this supports the mean reverting process. The findings of EGARCH and GJR-GARCH models show that the series have leverage effect, and the impact of the shocks is asymmetric, and that means the impact of negative shocks on volatility are higher than positive shocks of the same size. This finding is consistent with the literature.

Future research should explore a comparison of the volatility of major stock index returns such as Nasdaq-100 with commodity index returns to determine whether the latter may be used in the context of risk management. 


\section{Acknowledgments}

This research was undertaken within the Fulbright Visiting Scholar Program. We acknowledge the opportunity provided by the United States Department of State, Bureau of Educational and Cultural Affairs (ECA).

\section{Author Contributions}

All authors contributed equally to all aspects of the research reported in this paper.

\section{Conflicts of Interest}

The authors declare no conflict of interest. 


\section{References}

Aliyev, F. (2019). Testing Market Efficiency with Nonlinear Methods: Evidence from Borsa Istanbul. International Journal of Financial Studies, 7(2), 27. doi:10.3390/ijfs7020027

Andersen, T.G., Bollerslev, T., 1997. Intraday periodicity and volatility persistence in financial markets. Journal of Empirical Finance 4, 115-158.

Andersen, T. G., Bollerslev, T., Diebold F. X., and Ebens, X., 2001. The Distribution Of Realized Stock Return Volatility, Journal of Financial Economics, 61(1), 43-76, doi:10.1016/S0304-405X(01)00055-1

Bollerslev, T. (1986). Generalized Autoregressive Conditional Heteroscedasticity. Journal of Econometrics, 31, 307-327. DOI: 10.1016/0304-4076(86)90063-1

Brooks C., (2008) "Introductory Econometrics for Finance: Second Edition" Cambridge University Press

Campbell, John Y., Andrew W. Lo, and Craig MacKinlay. 1997. The Econometrics of Financial Markets. Princeton: Princeton University Press.

Caporale, G. M. and Gil-Alana, L. A. (2012), Estimating persistence in the volatility of asset returns with signal plus noise models. International Journal of Finance and Economics, 17: 23-30. doi:10.1002/ijfe.441

Carlin C. F. Chu and K. P. Lam (2011). Modeling intraday volatility: A new consideration. Journal of International Financial Markets, Institutions and Money, 21(3), 388-418, DOI: 10.1016/j.intfin.2011.01.002

Chang, T. C., Wang, H., \& Yu, S. (2019). A GARCH model with modified grey prediction model for US stock return volatility. Journal of Computational Methods in Sciences and Engineering, 19:1, 197-208, DOI: 10.3233/JCM-180884

Chris Brooks \& Simon P. Burke (2003) Information criteria for GARCH model selection, The European Journal of Finance, 9:6, 557-580, DOI: 10.1080/1351847021000029188

Chun-Hung Chen; Wei-Choun Yu and Eric Zivot (2012). Predicting stock volatility using after-hours information: Evidence from the NASDAQ actively traded stocks. International Journal of Forecasting, 28 (2), 366-383, DOI: 10.1016/j.ijforecast.2011.04.005.

Dickey, David A., and Wayne A. Fuller. 1981. Likelihood Ratio Statistics for Autoregressive Time Series with a Unit Root. Econometrica 49: 1057-72. DOI: 10.2307/1912517

Emrah Altun (2018): A new approach to Value-at-Risk: GARCH-TSLx model with inference, Communications in Statistics - Simulation and Computation, DOI: 10.1080/03610918.2018.1535069

Engle, Robert F. 1982. Autoregressive conditional heteroscedasticity with estimates of the variance of United Kingdom inflation. Econometrica 50: 987-1007.

Engle, Robert F. 1982. Autoregressive conditional heteroscedasticity with estimates of the variance of United Kingdom inflation. Econometrica 50: 987-1007, DOI: 10.2307/1912773

Engle, Robert F. and Victor K. Ng, 1993, Measuring and testing the impact of news on volatility, Journal of Finance, 48, 1749-1778. DOI: 10.1111/j.1540-6261.1993.tb05127.x 
Erginbay Ugurlu, Eleftherios Thalassinos and Yusuf Muratoglu (2014). Modeling Volatility in the Stock Markets using GARCH Models: European Emerging Economies and Turkey, International Journal of Economics \& Business Administration, Volume II, Issue 3, 72-87

Franses, Philip Hans, and Dick van Dijk. 2000. Nonlinear Time Series Models in Empirical Finance. Cambridge: Cambridge University Press.

Glosten, L.R., Jagannathan, R. And Runkle, D. (1993) “On The Relation Between the Expected Values and the Volatility of The Nominal Excess Return on Stocks"'., Journal of Finance 48, 1779-1801, DOI: 10.1111/j.1540-6261.1993.tb05128.x

John D. Levendis (2018) Time Series Econometrics: Learning Through Replication Springer Texts in Business and Economics, ISSN 2192-4333, DOI: 10.1007/978-3-319-98282-3

Koy, Ayben and Ekim, Samiye, (2016) Borsa Istanbul Sektör Endekslerinin Volatilite Modellemesi, Trakya Üniversitesi İktisadi ve İdari Bilimler Fakültesi E-Dergi, Vol 5 No 2. Available at SSRN: https://ssrn.com/abstract=2991912

Kumar Narayan, Paresh. 2005. Are the Australian and New Zealand stock prices nonlinear with a unit root? Applied Economics 37: 2161-66. DOI: 10.1080/00036840500217887

Maciej Augustyniak, Luc Bauwens \& Arnaud Dufays (2018) A New Approach to Volatility Modeling: The Factorial Hidden Markov Volatility Model, Journal of Business $\mathcal{E}$ Economic Statistics, DOI: 10.1080/07350015.2017.1415910

Mandelbrot, B. (1963). The Variation of Certain Speculative Prices. The Journal of Business, 36(4), 394419. Retrieved from http://www.jstor.org/stable/2350970

Nasdaq: NDX $\quad$ vs $\quad$ SPX $\quad$ (2019, $\quad$ August $\quad 5) \quad$ Retrieved from https://business.nasdaq.com/marketinsite/2018/GIS/NDX-Vs-SPX.html

Nelson, D. (1991). Conditional Heteroskedasticity in Asset Returns: A New Approach. Econometrica, 59(2), 347-370. doi:10.2307/2938260

Peter Molnár (2016) High-low range in GARCH models of stock return volatility, Applied Economics, 48:51, 4977-4991, DOI: 10.1080/00036846.2016.1170929

Phillips, P. C., \& Perron, P. (1988). Testing for a unit root in time series regression. Biometrika, 75(2), 335-346, DOI:10.1093/biomet/75.2.335

Pierre Cizeau, Yanhui Liu, Martin Meyer, C.-K. Peng, H. Eugene Stanley (1997), Volatility distribution in the S\&P500 stock index, Physica A: Statistical Mechanics and its Applications Volume 245, Issues 3-4, 1 November 1997, Pages 441-445, DOI: 10.1016/S0378-4371(97)00417-2

Suliman Zakaria Suliman Abdalla, Peter Winker, Modelling Stock Market Volatility Using Univariate GARCH Models: Evidence from Sudan and Egypt, International Journal of Economics and Finance, Vol. 4, No. 8 (2012), DOI:10.5539/ijef.v4n8p161

Tsay, R. S. (2010). Analysis of Financial Time Series. 3rd Edition New York, United States of America, John Wiley \& Sons, Inc. DOI: 10.1002/9780470644560 
Yang K. Lu, Pierre Perron (2010) Modeling and forecasting stock return volatility using a random level shift model, Journal of Empirical Finance, Vol. 17, Issue 1, Pages 138-156, DOI: 10.1016/j.jempfin.2009.10.001

Zivot, E (2008), Practical Issues in the Analysis of Univariate GARCH Models, No UWEC-2008-03FC, Working Papers, University of Washington, Department of Economics, https://EconPapers.repec.org/RePEc:udb:wpaper:uwec-2008-03-fc.

Zivot E (2009) Practical Issues in the Analysis of Univariate GARCH Models. In: Mikosch T., Kreiß JP., Davis R., Andersen T. (eds) Handbook of Financial Time Series. Springer, Berlin, Heidelberg, DOI: 10.1007/978-3-540-71297-8_5

Appendix 1: GARCH $(1,1)$ model output

\begin{tabular}{crrrc}
\hline \multicolumn{5}{c}{ Mean Equation } \\
\hline Variable & Coefficient & Std. Error & z-Statistic & Prob. \\
\hline C & 0.000915 & 0.000123 & 7.449464 & 0 \\
\hline AR(1) & 0.812776 & 0.090871 & 8.944287 & 0 \\
\hline MA(1) & -0.84216 & 0.083081 & -10.13659 & 0 \\
\hline \multicolumn{5}{c}{ Variance Equation } \\
\hline$\alpha_{1}$ & 0.090591 & 0.008767 & 10.33333 & 0 \\
\hline$\beta_{1}$ & 0.906023 & 0.008707 & 104.0517 & 0 \\
\hline T-DIST. DOF & 8.183868 & 0.948724 & 8.626183 & 0 \\
\hline
\end{tabular}

Appendix 2: The sign bias test results

\begin{tabular}{ccccc}
\hline Variable & Coefficient & Std. Error & t-Statistic & Prob. \\
\hline $\mathrm{C}$ & 0.000194 & $1.40 \mathrm{E}-05$ & 13.89 & 0 \\
\hline$\varphi_{1}$ & 0.000112 & $1.98 \mathrm{E}-05$ & 5.671 & 0 \\
\hline
\end{tabular}

Appendix 3: The negative size bias test results

\begin{tabular}{ccccc}
\hline Variable & Coefficient & Std. Error & t-Statistic & Prob. \\
\hline C & $2 \mathrm{E}-04$ & $1.10 \mathrm{E}-05$ & 14.0767 & 0 \\
\hline $\boldsymbol{\varphi}_{\mathbf{1}}$ & -0.016 & 0.00093 & -17.634 & 0 \\
\hline
\end{tabular}

Appendix 4: The joint test results for sign and size bias

\begin{tabular}{ccccc}
\hline Variable & Coefficient & Std. Error & t-Statistic & Prob. \\
\hline C & 0.000106 & $1.80 \mathrm{E}-05$ & 5.91307 & 0 \\
\hline $\boldsymbol{\varphi}_{\mathbf{1}}$ & $-2.59 \mathrm{E}-05$ & $2.60 \mathrm{E}-05$ & -0.995374 & 0.3196 \\
\hline $\boldsymbol{\varphi}_{\mathbf{2}}$ & -0.019351 & 0.001107 & -17.48076 & 0 \\
\hline $\boldsymbol{\varphi}_{\mathbf{3}}$ & 0.009092 & 0.001232 & 7.379622 & 0 \\
\hline
\end{tabular}




\section{Appendix 5: The EGARCH model output}

\begin{tabular}{crrrr}
\hline \multicolumn{5}{c}{ Mean Equation } \\
\hline Variable & Coefficient & Std. Error & z-Statistic & Prob. \\
\hline C & 0.000604 & 0.00014 & 4.367597 & 0.000 \\
\hline \multicolumn{5}{c}{ Variance Equation } \\
\hline$\alpha_{0}$ & -0.20936 & 0.02111 & -9.91938 & 0.000 \\
\hline$\gamma$ & 0.122569 & 0.01274 & 9.620348 & 0.000 \\
\hline$\alpha_{1}$ & -0.11935 & 0.00941 & -12.6904 & 0.000 \\
\hline$\beta_{1}$ & 0.987505 & 0.00191 & 517.8731 & 0.000 \\
\hline T-DIST. DOF & 8.934735 & 1.0405 & 8.587002 & 0.000 \\
\hline
\end{tabular}

\section{Appendix 6: The GJR-GARCH model output}

\begin{tabular}{ccccc}
\hline \multicolumn{5}{c}{ Mean Equation } \\
\hline Variable & Coefficient & Std. Error & z-Statistic & Prob. \\
\hline $\mathrm{C}$ & 0.000575 & 0.000142 & 4.036237 & 0.0001 \\
\hline \multicolumn{5}{c}{ Variance Equation } \\
\hline$\alpha_{0}$ & $1.74 \mathrm{E}-06$ & $3.00 \mathrm{E}-07$ & 5.793885 & 0.000 \\
\hline$\alpha_{1}$ & -0.000546 & 0.008422 & -0.06484 & 0.948 \\
\hline$\gamma$ & 0.153715 & 0.014162 & 10.85374 & 0.000 \\
\hline$\beta_{1}$ & 0.911589 & 0.008224 & 110.8396 & 0.000 \\
\hline T-DIST. DOF & 9.285929 & 1.204098 & 7.711939 & 0.000 \\
\hline
\end{tabular}

